\title{
Hérnia de Littré causando obstrução intestinal
}

\section{Littré hernia causing bowel obstruction}

\author{
Heitor Soares de Souza, tCBC-MS”; Ana Carla Felício²; Guilherme Berthier ${ }^{3}$
}

\section{INTRODUÇÃO}

O Divertículo de Meckel é um remanescente do ducto onfalomesentérico que, no embrião, estabelece uma comunicação entre o saco vitelino e a luz intestinal ${ }^{1}$. Vem a ser a mais freqüente anomalia congênita do trato gastrintestinal, com incidência variando em torno de $2 \%$. Em $60 \%$ dos casos, suas complicações se manifestam antes do segundo ano de vida ${ }^{3}$.

Em 1700 Alexis Littre descreveu a hérnia que leva seu nome. Dois tipos foram relatados: a Hérnia de Littre Combinada (Divertículo de Meckel acompanhado de outras vísceras no saco herniário) e a Hérnia de Littre Verdadeira (somente o Divertículo de Meckel no saco herniário) ${ }^{3}$. É mais prevalente no sexo masculino, na proporção de $3: 2{ }^{1}$, incidindo da seguinte forma: $50 \%$ em região inguinal, $20 \%$ em região femoral, $20 \%$ em região umbilical e $10 \%$ em outros locais.

\section{RELATO DO CASO}

Paciente do sexo masculino (C.R), 60 anos, foi admitido no Pronto Socorro da Santa Casa de Campo Grande com quadro clínico de abdômen agudo obstrutivo - náuseas, vômitos e distensão abdominal. Ao exame físico revelou-se massa palpável dolorosa em região inguinal direita, irredutível, não pulsátil, que aparecera 03 dias antes, durante esforço físico. Indicou-se herniorrafia inguinal de urgência.

Com o paciente sob raquianestesia, foi realizada inguinotomia direita com cerca de $6 \mathrm{~cm}$, diérese por planos e hemostasia. À exploração do saco herniário, constatouse presença de segmento de íleo com Divertículo de Meckel e sofrimento vascular (Figura1). Ressecou-se o segmento afetado, realizando-se enteroanastomose término-terminal e herniorrafia.

A análise anátomo-patológica da peça de intestino delgado medindo $18 \times 3 \times 2 \mathrm{~cm}$, revelou formação diverticular de $4 \times 2 \times 2 \mathrm{~cm}$ (Figura 2), confirmando o diagnóstico trans-operatório. O paciente evoluiu bem, sem intercorrências no pós-operatório.

\section{DISCUSSÃO}

Durante a vida intra-uterina, o conduto onfalomesentérico (COM) estabelece uma comunicação entre o saco vitelino e a luz intestinal, na união dos intestinos médio e posterior, com a função de nutrir o embrião ao longo da segunda e terceira semanas de gestação, enquanto a circulação útero-placentária ainda não está bem desenvolvida. Entre a $5^{\mathrm{a}}$ e a $7^{\mathrm{a}}$ semanas ocorre a obliteração do COM, resultando na formação de um tecido fibroso que, mais tarde, desaparecerá por apoptose. No entanto, todo ou parte do conduto poderá persistir e dar origem às várias formas dos remanescentes do conduto onfalomesentérico ${ }^{2}$. Meckel descreveu em 1808 a persistência proximal do COM, caracterizando o divertículo que leva seu nome. Vem a ser a mais freqüente anomalia congênita do trato gastrintestinal,

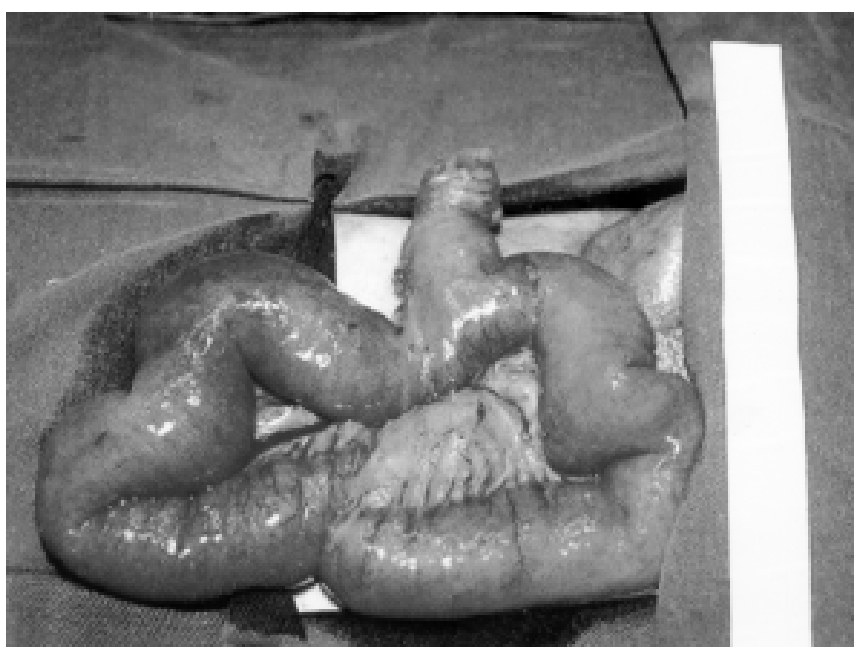

Figura 1 - Fotografia do campo operatório - Inguinotomia direita - com a alça de delgado e o divertículo de Meckel, caracterizando a Hérnia de Littre.

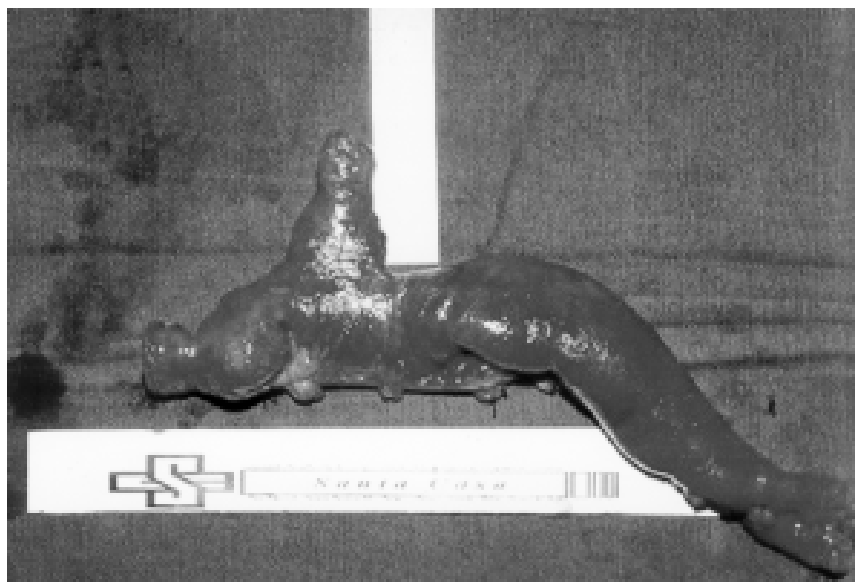

Figura 2 - Peça cirúrgica.

Trabalho realizado na ABCG - Santa Casa de Campo Grande - MS.

1. Coordenador do Programa de Residência Médica em Cirurgia Geral da Santa Casa de Campo Grande - MS - BR; 2. Médica residente em Angiologia e Cirurgia Vascular Periférica da Santa Casa de Campo Grande - MS - BR; 3. Estagiário em Cirurgia Geral do Hospital Stella Maris de Guarulhos - SP - BR. 
com incidência variando em torno de $3 \%$, e é responsável por cerca de $6 \%$ dos casos de obstrução intestinal aguda na infância ${ }^{5}$. Em $60 \%$ dos casos, suas complicações se manifestam antes do segundo ano de vida ${ }^{5}$.

Em 1700 Alexis Littre descreveu a hérnia que leva seu nome ${ }^{1}$. Dois tipos foram relatados: a Hérnia de Littre Combinada (Divertículo de Meckel acompanhado de outras vísceras no saco herniário) e a Hérnia de Littre Verdadeira (somente o Divertículo de Meckel no saco herniário). É mais predominante no sexo masculino, na proporção de 3:18, incidindo da seguinte forma: $50 \%$ em região inguinal; $20 \%$ em região femoral; $20 \%$ em região umbilical e $10 \%$ em outros locais. Os sintomas que acompanham esta afecção são normalmente vagos e tardios, sendo seu diagnóstico feito durante o ato cirúrgico ${ }^{4}$. Em um estudo feito em Manipal, Índia, foram documentados 21 casos de Divertículo de Meckel em crianças desde 1981, dentre os quais apenas dois apresentaram Hérnia de Littre ${ }^{1}$.

Seu tratamento é cirúrgico, compreendendo a ressecção da região acometida e fechamento transverso da alça'.

A Hérnia de Littre é um evento muito raro, por ser o Divertículo de Meckel infreqüente e o estrangulamento herniário não ser comum. O diagnóstico é feito no intra-operatório, já que não existem sinais patognomônicos desta entidade ${ }^{4}$.

O tratamento é cirúrgico, compreendendo a ressecção da região acometida e fechamento transverso da alça.

\title{
A B S T R A C T
}

\begin{abstract}
The authors describe a case of a 60-year-old male with a history of a mass and pain at the right inguinal and epigastric areas. He also reported symptoms of bowel obstruction. Physical examination revealed a mass at right inguinal area, which was not reducible or pulsatile. Surgical findings included hernial sac contents with loop of ileum with signs of ischemia and a Meckel's diverticulum. Histopathological examination showed herniation of the Meckel diverticulum -Littré hernia. The article discusses the history and the incidence of this rare form of hernia.
\end{abstract}

Key words: Hernia, inguinal. Meckel diverticulum. Intestinal obstruction.

\section{REFERENCIAS}

01. Cirillo F, Troiano L, Mortini B, Agarossi M, Riboldi O. Ernia Inguinale con diverticolo di Meckel strozzato (ernia del Littré). Minerva Chir. 1991; 46(11):627-30.

02. Martín-Pérez E, Fernández-Arjona M, Pérez-García A Leiomyosarcoma in a Littre's hernia. Eur J Surg. 1993; 159(8):4456.

03. Acea Nebril B, Blanco Freire N, Budiño Ramos J, Corbal Ramos G, Taboada Filgueira L, Gómez Freijoso C. Hernia de Littré crural mixta. Significación pronóstica. Rev Esp Enferm Dig. 1994; 86(5):860-1.

04. Gesmundo R, Bertotti I, Bevilacqua A, Maiullari E, Moro G. Su un caso di ernia di Littré strozzata in sede inguinale destra. Minerva Chir. 1988; 43(10):875-6.

05. Trupo FJ, Aburahma A. Meckel's diverticulum in a femural hernia: a Littre's hernia. South Med J. 1987; 80(5):655-6.
Recebido em 20/03/2006

Aceito para publicação em 15/05/2006

Conflito de interesse: nenhum

Fonte de financiamento: nenhuma

\section{Como citar este artigo:}

Souza HS, Felício AC, Berthier GA. Hérnia de Littré causando obstrução intestinal. Rev Col Bras Cir. [periódico na Internet] 2008; 35(5). Disponível em URL: http://www.scielo.br/rcbc

Endereço para correspondência:

Dr. Heitor Soares de Souza

E-mail: heitorss@terra.com.br 